\title{
The Sustainable Development of Modern Railway Transportation Planning and Management Under the Guidance of COM Technology
}

\author{
Ming YANG ${ }^{\mathrm{a}}$ and Anliang $\mathrm{LONG}^{\mathrm{b}}$ \\ ${ }^{a}$ School of Foreign Languages, East China Jiaotong University, China \\ ${ }^{\mathrm{b}}$ School of Foreign Languages, East China Jiaotong University, China
}

\begin{abstract}
In order to improve the planning and management ability of railway transportation and establish a sustainable railway transportation system, a modern railway transportation planning and management system is established by component object model (COM) technology to achieve efficient and sustainable management scheme. First, based on COM technology, the geographic information system (GIS) component is designed and a visual map query scheme is established. GIS can be used to query and dynamically operate maps to obtain rich visual data. Then, based on GIS technology, the railway transportation management system is established from the data access layer, business logic layer and interface presentation layer. The front-end GIS system can quickly access the spatial data and attribute data of the railway, and realize the visual query and management of the railway transportation. Finally, the performance of railway transportation planning management system is tested. The results show that through the planning of X city's container capacity in 2018, the optimized railway carrying capacity has been greatly improved compared with the original capacity. In addition, through the planning of railway transportation frequency, the number of railway trains is reduced from 141 to 42, which effectively reduces the consumption of railway resources. Therefore, the railway planning management system designed can effectively maximize the use of railway transportation capacity, reduce the consumption of resources in the process of railway operation, and realize the construction of efficient energy-saving and sustainable railway transportation network. This study can provide a reference for the construction of a new sustainable railway development model.
\end{abstract}

Keywords. Railway transportation, COM component, sustainable development, GIS technology

\section{Introduction}

Sustainable development is a new model of human development that has attracted the attention of the international community in recent years. It has transformed social development from a purely economic development goal to a coordinated development model of society, economy and resources. The overall goal of sustainable development

${ }^{1}$ Ming YANG, School of Foreign Languages of East China Jiaotong Universitey, 808 Shuanggang Dongdajie, Nanchang, Jiangxi, China; Email: 65358170@qq.com 
is to maintain the coordination between economic development and natural environment resources. China has made sustainable development an important strategy for the future development of the country. Moreover, China's national conditions and the development of railway transportation also determine that modern railway transportation needs to develop sustainable transportation. However, the problems of energy consumption and environmental pollution brought by the development of railway transportation have a huge negative impact on the society. With the continuous increase of China's railway operation mileage and the rapid development of high-speed railway and urban rail transit construction, the main development direction of railway transportation construction in the future is to realize the coordination of railway transportation infrastructure construction and environmental protection, and carry out sustainable development of railway transportation planning and construction [1-3].

In order to study the impact of urban growth and urbanization on urban planning, Farooq et al. (2018) established the identification transportation network to judge the current traffic flow and traffic handling capacity, and established a transportation model between Beijing and Xiong'an, so as to increase the connection and connectivity, reduce the travel time, and increase the transfer capacity between Beijing and Xiong'an. Through the analysis of the existing traffic network between the two cities, the network that could meet the future demand was proposed. The first stage was to use geographic information system (GIS) to study various options and plan the public transport system. The second stage was to use analytic hierarchy process (AHP) to evaluate multiple options and evaluate the alternatives. The results show that travel time, travel cost, safety, reliability and environment are the key standards of urban planning [4]. Yin et al. (2017) studied the theoretical development and practical implementation of automatic train operation technology, and introduced the background of automatic train operation technology, including the development and implementation of automatic train operation technology in urban subway system, and the basic characteristics and basic structure of typical automatic train operation technology system. The research was divided into three main aspects: train operation modeling technology, train trajectory optimization and train speed control method. Finally, the emerging requirements of the current automatic train operation technology system and the most promising research directions in the future are discussed, including the implementation of automatic train operation technology on trunk lines and high-speed railways, cooperative train operation methods for energy-saving problems, and the combination of railway traffic control and advanced automatic train operation technology [5]. Carydi (2019) investigated the impact of railway reconstruction on the urbanization process in the northwestern Peloponnesian peninsula, discussed how the railway could become an effective and competitive factor by developing local synergy within the geographical characteristics of its affected areas. In order to conceptualize the description of synergies that directly or indirectly affect railway restructuring, a new observation scale was proposed. The concept of "service ecology" played a role of observation scale. The results show that the development of integrated railway does not depend on the optimization of single infrastructure elements or territory scale, but on the well-planned network infrastructure comprehensive pattern. This pattern can not only provide travel services, but also shape space, regulate traffic and interact with participants. The study provides a reference for the alternative working scheme of high-efficiency and cost-effective railway connection of the northwest Peloponnesian railway [6]. 
In order to explore the sustainable development of railway transportation planning and management system, a railway transportation planning and management system based on GIS technology is designed, and component object model (COM) technology is used design the GIS system. This design can improve the visual query and control ability of the railway transportation planning and management system, and can be used in different operating systems and programming environments. The functional modules involved are introduced in detail. Finally, the planning management performance of the designed railway transportation system is tested.

\section{Method}

\subsection{Design of GIS Component Based on COM Technology}

GIS is a technology that combines geography, remote sensing, computer science and cartography, which involves spatial data acquisition, processing and analysis. Through the organic combination of these disciplines, combined with the basis of geospatial database, different spatial data sources and non-spatial data, it provides the scheme of planning and management services through model analysis. Figure 1 shows the structure of GIS system. GIS can be used to realize the dynamic link of graphics, images and attribute data under the spatial framework, carry out visual query and spatial analysis functions, and store, retrieve and display the acquired data information, so as to provide fast, efficient and visual decision support for enterprises. Users can query and dynamically operate the map through GIS, and obtain rich visual data [7-10].

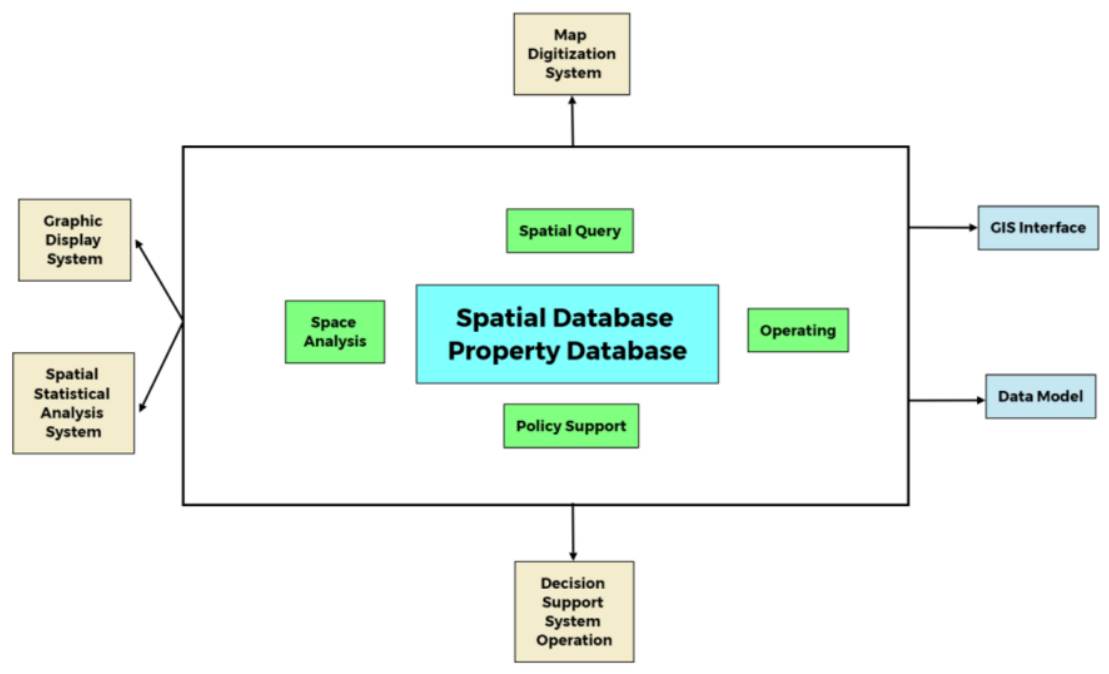

Figure 1. The structure of GIS system.

GIS is a comprehensive information decision-making system, including spatial database and information database management system, graphic display and image processing system, spatial query and statistical analysis system of geographic data, map digitization system and decision support system. 
(1) Spatial database and information database machine management system is to store and manage spatial data and attribute data in GIS. Spatial data refers to geometric data of geographical entities; attribute data refers to non-geometric qualitative data and quantitative data. Through this system, the spatial data and attribute data of a region's geography test will be associated.

(2) The graphic display and image processing system is to display the information database elements of spatial database in the form of vector electronic map, which can realize the functions of map layering, unlimited enlargement and reduction, roaming and output.

(3) The spatial query, statistics and analysis system of geographic data is to query the spatial location information according to the spatial geographical entities and their attributes. The statistics and analysis realize the exploration and combination of the network relationship and topological relationship of the geographical examination questions.

(4) Map digitization system can be used to obtain and input GIS spatial data.

(5) Decision support system can provide decision support for the results of spatial query and spatial analysis.

COM refers to the interface specification of communication between components, which is a binary and network specification formulated by Microsoft. Through COM components, communication can be carried out between any two components. Therefore, through the COM component, communication can be carried out in any computer, operating system and programming language. Therefore, GIS is encapsulated by component interface technology, that is, users can carry out secondary development of controls or automatic servers through software without knowing spatial data and related processing algorithms, and customize software interface and service functions that meet their own needs [11-15].

In COM specification, COM object and COM interface are two important contents. $\mathrm{COM}$ objects rely on the corresponding $\mathrm{COM}$ interface for external transmission services, and encapsulate the service functions. COM interface is a collection of some member functions, and its concrete implementation is realized by corresponding objects. A COM object can interface with multiple COM, and can realize the functions of interface query and application technology. In the COM model, a COM component has multiple COM objects, and each COM object has one or more COM interfaces. Each interface also supports and contains a variety of functions to complete specific tasks. Figure 2 shows the structure. The communication between COM objects is accomplished through the interface.

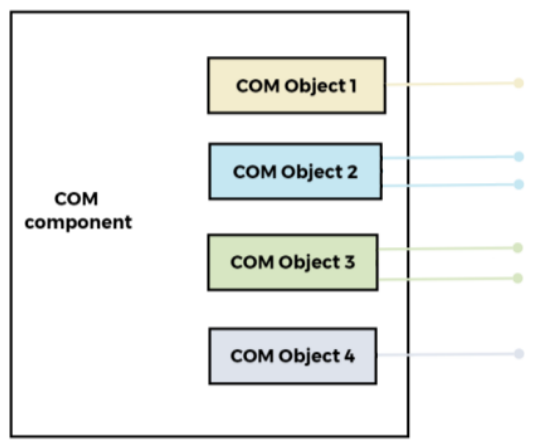

Figure 2. The relationship among COM object, COM component and COM interface. 
The basic idea of components GIS (COMGIS) is to divide the major functions of GIS system, and each component corresponds to different functions. Various GIS components and non-components can be developed and integrated by visual software to form customized GIS components.

Vector graphics module is the most important part of GIS. A vector graphics module should have the following functions: input and output function of graphics, display function of graphics, perfect drawing function, selection function of graphic objects, and graphic editing function. To implement these functions, a set of classes is needed. There will be a large number of primitive classes in the map, which form a class respectively. For the convenience of management, the elements with common properties are combined into primitive base class. The map class holds the pointer of a set of straight-line layer classes. Each layer contains a set of pointers to the primitive class, which in turn points to the primitive. Figure 3 shows the relationship between them.

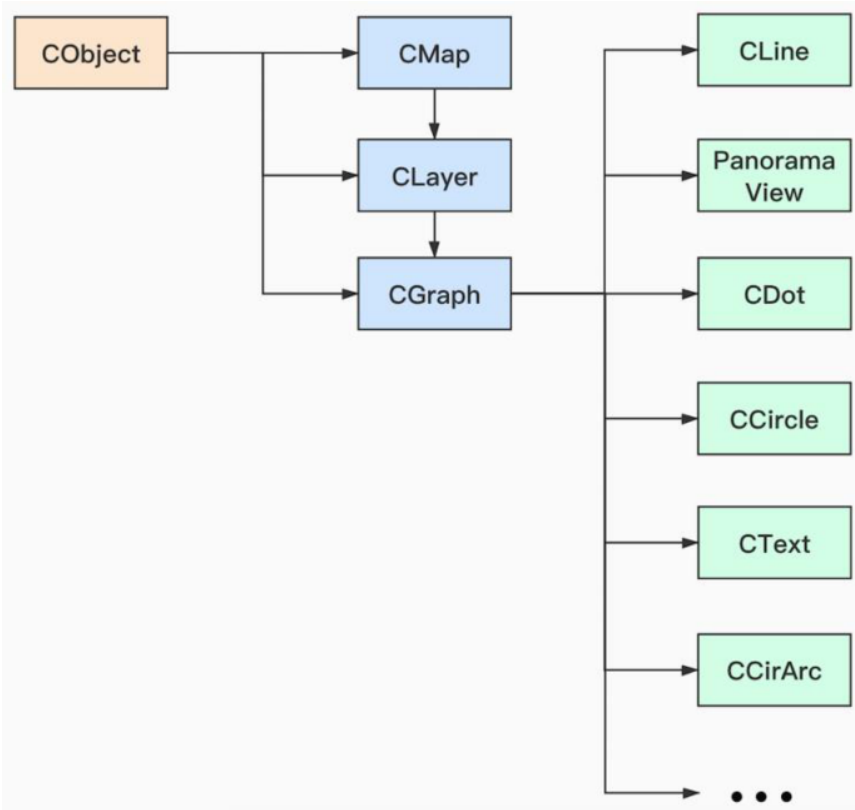

Figure 3. Diagram of vector graphics component class.

The design of vector graphics component class adopts the idea of divide and rule to layer the map. Each layer only manages the display operation of the data and metadata of this layer, and the operations of various primitive are encapsulated in the interior. Therefore, each layer can only call its own properties, which simplifies the understanding of the map layer on the details of the primitive [16-20].

\subsection{Design of Railway Transportation Management System Based on GIS Technology}

Through the investigation on the functional requirements of employees, the railway resources integrated management system needs to meet the comprehensive and visual management of railway transportation resources within the jurisdiction. It is necessary to meet the principles of systematization, expansibility, openness, practicality, 
economy, confidentiality and flexibility to analyze the current changes of railway transportation by using railway resources integrated management system.

The railway transportation integrated management system is divided into data access layer, business logic layer and interface presentation layer. Figure 4 shows its structure.

Data access layer includes spatial data, attribute data and multimedia data. Data can be modified and business logic layer can be directly accessed. Business logic layer is the core of the whole system, and it is the place where all business functions of the system realize the logic rules. The interface presentation layer is the interface layer for users to interact with the system. Through the interface presentation layer, the system functions are requested to operate, and the background results are displayed on the interface [21-24].

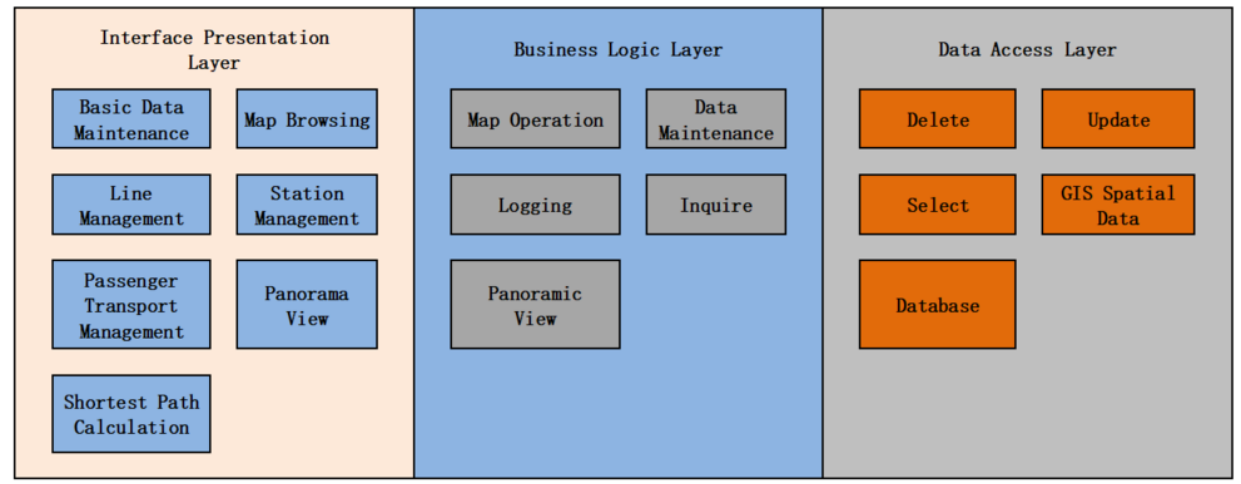

Figure 4. General structure of railway transportation management system.

(1) According to the analysis of overall architecture design and function of the railway transportation management system, the system data flow design is carried out. The design of the data flow process is as follows. Users can query and manage the railway resources in the management system by logging in the system. Railway data are stored in the database, the query results are displayed on the client interface, and can be highlighted on the railway network map, and can be exported as a data table. When the system is maintained, only the contents in the database need to be modified. Figure 5 shows the specific process.

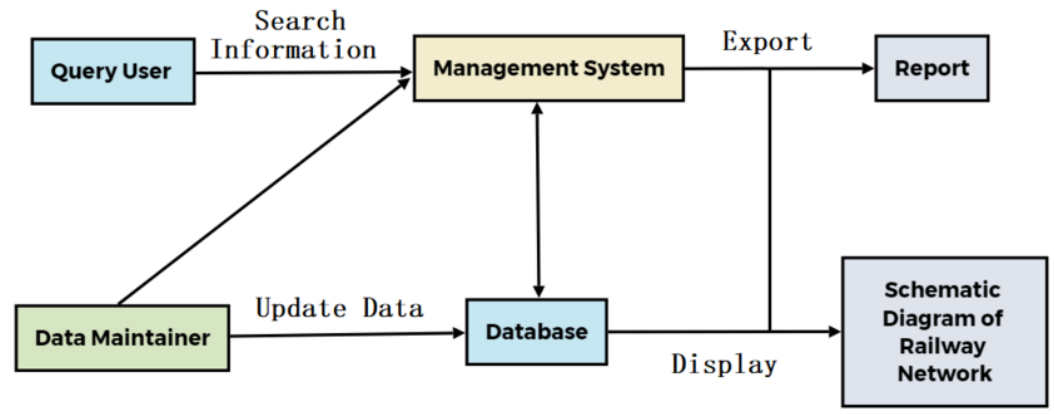

Figure 5. Data flow of railway transportation management system. 
(2) The design of business process provides a framework for the overall design of the application function of railway transportation system. The specific process is as follows. Maintenance personnel collect relevant data from various railway transportation enterprises and stations, and update the local database. Railway schematic map is used to display map service by GIS system. Media data is stored in the appropriate system folder. Users can log in the client to manage and query the railway transportation, and display it visually. Figure 6 is the business process.

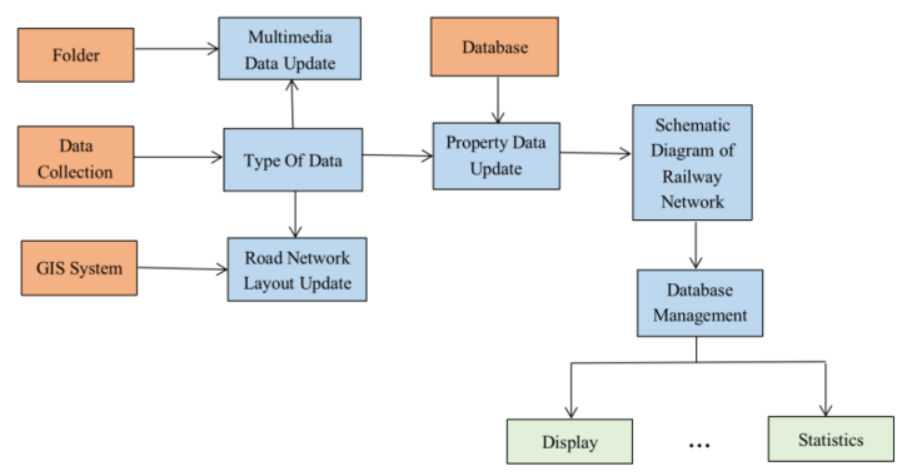

Figure 6. Business process of railway transportation management system.

(3) According to the system flow, the railway transportation system is designed as a combination of several modules, including basic data maintenance module, map browsing module, resource management module and report management module. Moreover, each module contains a variety of specific management modules. Through these modules, users can carry out various business operations and realize the query and management of railway spatial and attribute information. Figure 7 shows its overall functional architecture.

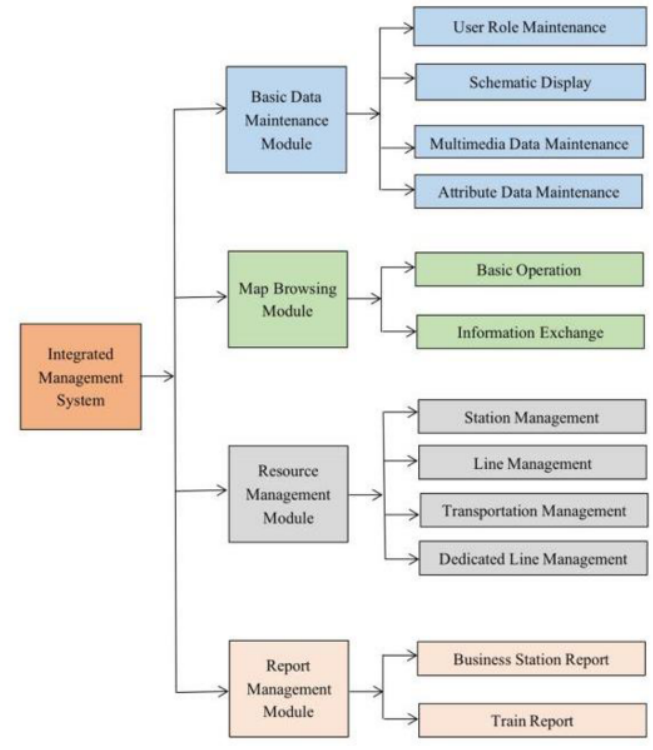

Figure 7. Functional structure of railway transportation management system 
(4) The basic data maintenance module is to modify the information of railway stations, transportation enterprises, passenger trains and transportation lines, and can realize batch import and output. Maps and panoramas of railway transportation are updated and maintained. Figure 8 shows the division of its structure and function.

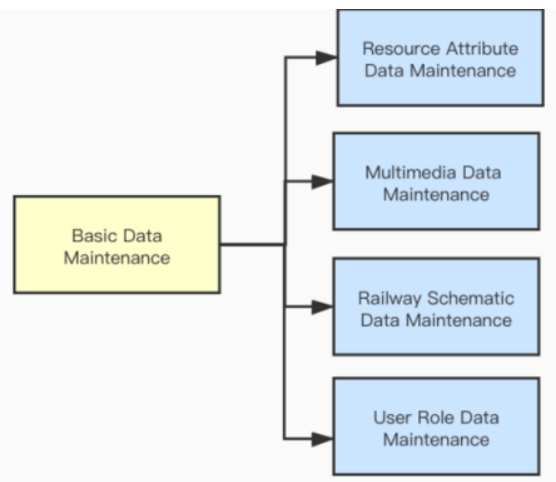

Figure 8. Function division of basic data maintenance module

(5) The map browsing module can zoom and pan the railway network schematic diagram, display the station, line, transportation status and other information on the map in real time, and locate the space and attributes of railway lines on the map. For example, after a station is input, the input station will be highlighted on the map, and the basic information of the station will be displayed, as well as the business processing status of the station. Figure 9 shows the specific function division.

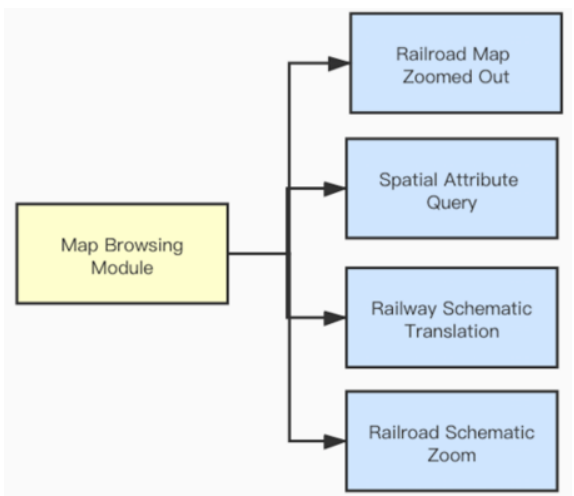

Figure 9. Function division of map browsing module

(6) Resource management module includes station management, line management, freight management, special line management and train management. Station management refers to the management of station information by relevant personnel, including combination query, special line query, passenger information query, freight information query, station plan and panorama. The line management includes the query of the basic information combination of the line, the query of the station between the two mileage on the line, and the query of the shortest route vehicle between the two places; for station query between two mileage, the line name can be selected first, and then two mileage values can be input. Clicking the query button can display all station 
information between the two mileage, and highlight the station inquired on the schematic diagram. The shortest path query function is to search the shortest path between the starting point and the ending point by calling the path analysis service, and highlight the shortest path found on the diagram. Freight management is to make statistics on the freight cars and goods information of each station, enterprise and line, plan and adjust the transportation line, and highlight each statistical information. Passenger management is to query the basic information of passenger train and train passing station, and display it on the map. Special line management can manage special lines and dangerous goods within the jurisdiction.

The railway resources integrated management system is developed according to the technical route of data collection and processing, attribute data and spatial data association, data access layer, business logic layer, interface access layer and improving system interface. Figure 10 shows the technical development route of railway transportation management system. Spatial data and attribute data are associated and displayed on railway information network. Through the spatial database engine, the local business data attribute database and spatial data are combined with each other, and the spatial data and attribute data can be accessed quickly by the front-end GIS system, so as to realize the visual query of railway resources $[25,26]$.

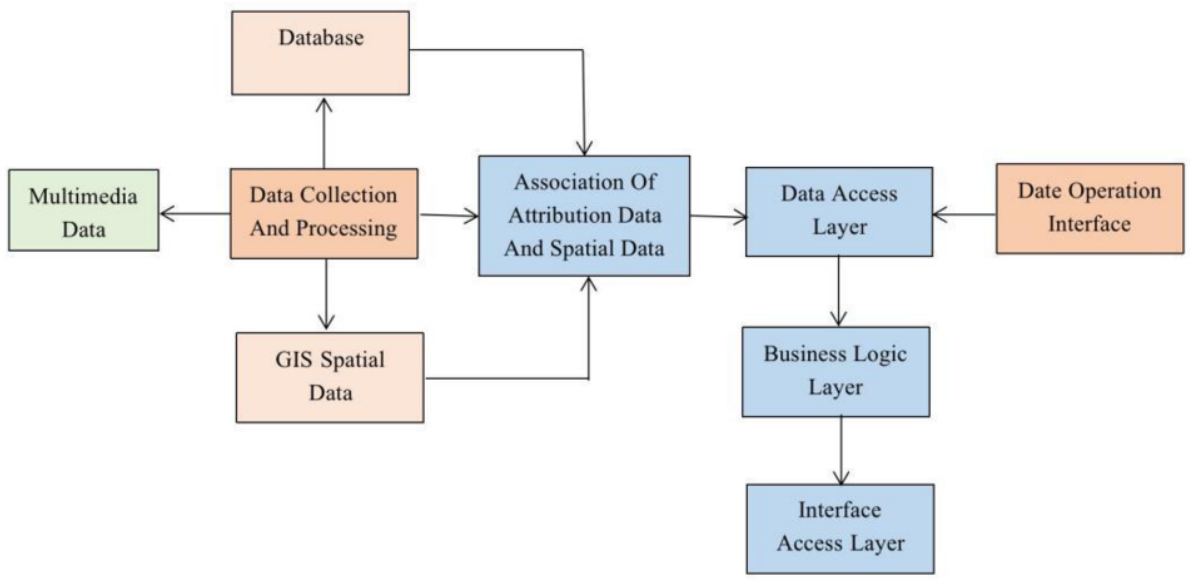

Figure 10. Technical development route of railway transportation management system

In terms of function, GIS is a geographic data information system for acquiring, storing, displaying and editing. Map editor is a data acquisition and input layer in GIS system, which can carry out a series of operations. Combined with the railway transportation planning management system, the efficient visual control of the existing railway resources can be realized. It is applied to a practical case to test the actual effect of planning management. In recent years, with the development of foreign trade, the railway container transportation has a large carrying capacity, but its mode is backward. In addition to the influence of economic structure and foreign trade transactions, it is also restricted by factors such as transportation time, train carrying capacity and service quality. Figure 11 shows the interface of railway transportation planning management system. 


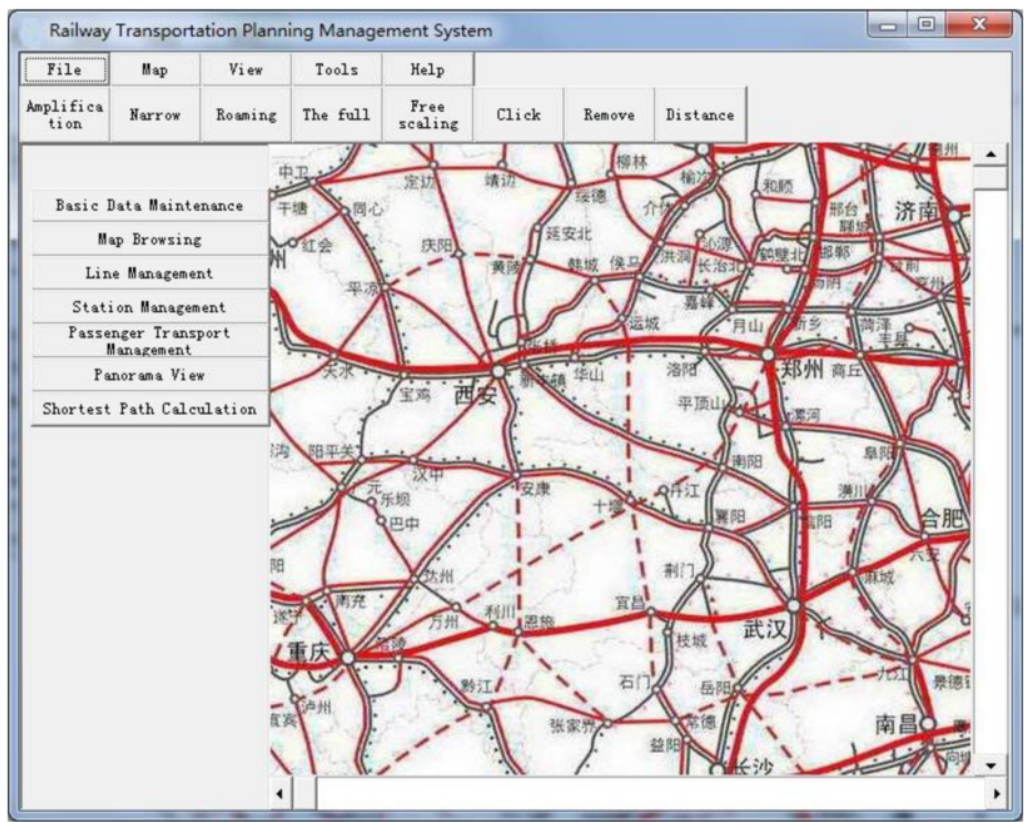

Figure 11. Interface diagram of railway transportation planning management system.

\section{Results and Discussion}

The designed railway transportation planning system is used to calculate the railway container carrying capacity from X city to each province in 2018, and compare the unplanned transportation situation. Figure 12 is the results.

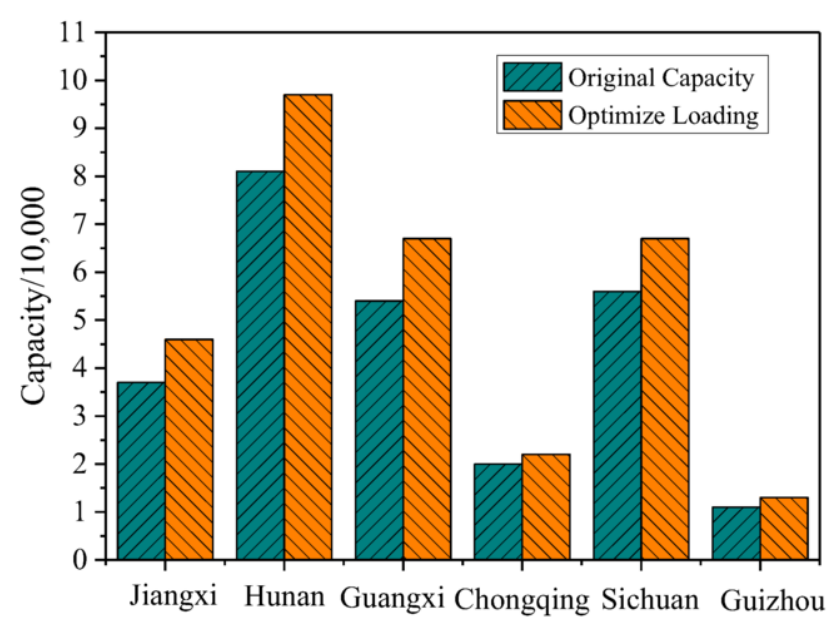

Figure 12. Optimization chart of $X$ city container capacity by railway transportation management system.

Figure 12 shows that different provinces have different demands on railway carrying capacity of $\mathrm{X}$ city, which may be due to the relative differences in railway 
container transport capacity and demand. After the railway transportation management system is used to optimize the transportation line, the railway container carrying capacity has been significantly improved. Therefore, the railway transportation planning management system can effectively optimize the railway carrying capacity and improve the overall carrying capacity.

According to the designed railway transportation planning management system, the line optimization test is carried out. Known conditions are as follows. There are 35 train sets, 70 containers for single deck train and 140 containers for double deck train. According to the calculation of the original traffic volume, 274 container lines need to be carried in the preliminary plan. Moreover, due to the limitation of loading time, most lines cannot meet the standard of one train every two weeks. Therefore, the designed management system is used to optimize the line, and Figure 13 is the results.

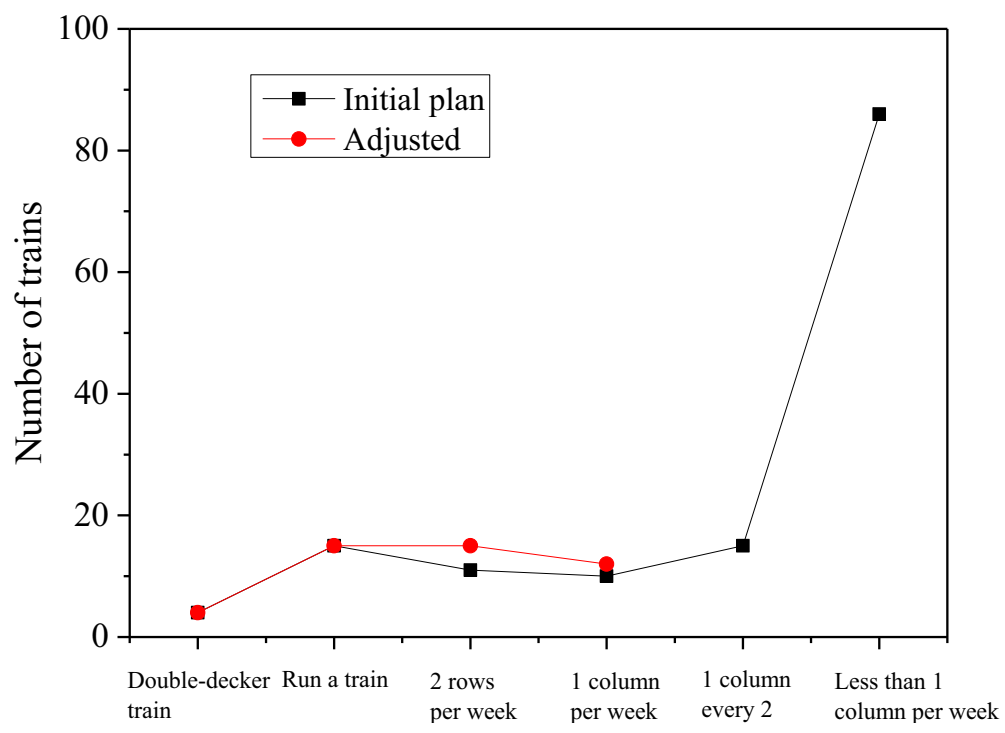

Figure 13. Line optimization map of railway transportation management system

Figure 13 shows that through the planning of the designed railway transportation system, the trains with smaller traffic volume are cancelled and incorporated into other lines. Before the adjustment, the total number of trains is 141, with 86 trains less than one train every two weeks. After the adjustment, the total number of trains is 42 , and there is no less than one train every two weeks. Therefore, through the planning of the line, the number of trains running is greatly reduced, which saves energy consumption.

To sum up, the optimization results of railway transportation planning management system on railway carrying capacity and railway operation line show that the designed planning management system can effectively maximize the use of railway transportation capacity, reduce the consumption of resources in the process of railway operation, and realize efficient, energy-saving and sustainable railway transportation network. 


\section{Conclusion}

In order to improve the ability of railway transportation planning and management, a sustainable planning and management system is established. First, the GIS system based on COM technology is designed to improve the visual query and control ability of GIS system. Then, based on GIS technology, the railway transportation management system is established from the data access layer, business logic layer and interface presentation layer, and the specific modules involved are introduced in detail to realize the visual query and management of railway transportation. Finally, the actual performance of the designed railway transportation planning management system is tested. The results show that the designed planning management system can effectively maximize the use of railway transportation capacity, reduce the consumption of resources in the process of railway operation, and realize the efficient, energy-saving and sustainable railway transportation network. Therefore, the designed planning management system can be used in railway management. However, there are still some deficiencies. There are still some optimization problems in the performance of the designed railway traffic planning management system, and errors may be reported in the operation process. Therefore, continuous optimization is needed in the follow-up experiments.

\section{References}

[1] Zhang YZ, Wang JQ, Hu ZA. Optimization Model of Transportation Product Selection for Railway Express Freight. Technol Rev. 2016 Oct:9(5):97-108.

[2] Guo D, He G, Lian Z. Environmental risk perception and public trust-from planning to operation for China's high-speed railway. J Sustain Forest. 2017 Mar:11(9): 696-706.

[3] Butko T, Muzykin M, Prokhorchenko A, et al. Determining the Rational Motion Intensity of Train Traffic Flows on the Railway Corridors with Account for Balance of Expenses on Traction Resources and Cargo Owners. J I Telecommun Prof. 2019 Jun:20(3): 215-228.

[4] Farooq A, Xie M, Stoilova S, et al. Transportation planning through GIS and multicriteria analysis: case study of Beijing and XiongAn. J Adv Transport. 2018 Oct:(1):16.

[5] Yin J, Tang T, Yang L, et al. Research and development of automatic train operation for railway transportation systems: A survey. Transport Res Rec. 2017 Dec:85: 548-572.

[6] Carydi I. Integrated Railway Planning in the North West Peloponnese: A Service Ecologies Perspective. Sensor Rev. 2019 Mar:55(1): 68-84.

[7] Kawasaki K. Recent Trends and Topics in Research and Development Related to Transportation and Traffic Planning Technology. Mis Quart. 2019 Mar:60(3): 153-156.

[8] Wey WM, Huang JY. Urban sustainable transportation planning strategies for livable City's quality of life. Tribol Int. 2018 Feb:82: 9-27.

[9] Jourquin B. Calibration and validation of strategic freight transportation planning models with limited information. Data Technol Appl. 2016 Feb:6(5): 239-256.

[10] Wey WM. Constructing urban dynamic transportation planning strategies for improving quality of life and urban sustainability under emerging growth management principles. Sustain Cities Soc. 2019 Jan:44: 275-290.

[11] Ghofrani F, He Q, Goverde RMP, et al. Recent applications of big data analytics in railway transportation systems: A survey. Transport Res Rec. 2018 Jan:90: 226-246.

[12] Nenad M. Maximum independent set in planning freight railway transportation. Emj-Eng Manag J. 2018 Feb:5(4): 499-506.

[13] Hamurcu M, Eren T. Transportation planning with analytic hierarchy process and goal programming. Coast Eng J. 2018 Nov:2(2): 92-97.

[14] Yatskiv I, Budilovich E. A comprehensive analysis of the planned multimodal public transportation HUB. Transport Sci. 2017 Jun:24: 50-57. 
[15] Rudi A, Fröhling M, Zimmer K, et al. Freight transportation planning considering carbon emissions and in-transit holding costs: a capacitated multi-commodity network flow model. Transport Res E-Log. 2016 Nov:5(2): 123-160.

[16] Abuobidalla O, Chen M, Chauhan S. A matheuristic method for planning railway freight transportation with hazardous materials. P I Mech Eng F-J Rai. 2019 Aug:10: 46-61.

[17] Kadam S, Bandyopadhyay P K, Patil Y. Mapping the field through bibliometric analysis of passenger centric railway transportation. Transport Res E-Log. 2016 Jun:2(4): 349-368.

[18] Pagliara F, Esposito M, Troisi C. Planning and designing transport infrastructures for sustainability: The great project NAPLEST. Radioengineering. 2017 Jan:45(2): 53-57.

[19] Lin DY, Tsai MR. Integrated crew scheduling and roster problem for trainmasters of passenger railway transportation. IEEE Access. 2019 Feb:7: 27362-27375.

[20] Feng HF, Cai-Hong LI, Wang R. Vulnerability study for public transport network of valley city: Case of Lanzhou. J. Transp. Syst. Eng. Inf. Technol. 2016 Feb:16: 217-222.

[21] Bayane BM, Yanjun Q, Bekhzad Y. A review and analysis of railway transportation system in the economic community of West African States: Towards the development of sustainable regional goal. Adv Comput. 2020 Feb:2(2): 011-022.

[22] Chege S M, Wang D, Suntu S L, et al. Influence of technology transfer on performance and sustainability of standard gauge railway in developing countries. J Am Soc Inf Sci Tec. 2019 Sep:56: 79-92.

[23] Kumar Y, Panchal S, Ashish A, et al. Feasibility study of railway line in hilly region using GIS. J. Transp. Syst. Eng. Inf. Technol. 2017 Aug:13(08): 183-191.

[24] Marcantonio RA, Golub A, Karner A, et al. Confronting inequality in metropolitan regions: Realizing the promise of civil rights and environmental justice in metropolitan transportation planning. Fordham Urb. LJ. 2017 Aug:44: 1017.

[25] Bayane BM, Yanjun Q. Transport infrastructure development in China. J Am Soc Inf Sci Tec. 2017 May:2(1): 29-39.

[26] Štefancová V, Nedeliaková E, López-Escolano C. Connection of dynamic quality modeling and Total Service Management in railway transport operation. Radioengineering. 2017 Sep:192: 834-839. 